\title{
Uma Estratégia de Reforma dos Processos de Reforma
}

PAULO C. COSTA MOURA *

Psicólogo

Entre as coisas desejáveis e necessárias à educação nacional, a Reforma Francisco Campos introduziu a idéia da criação dos Serviços de Orientação Educacional, instrumento "inadiável" para facilitar o ajustamento dos alunos à Escola. Hoje, passados quase 40 anos daquela "reforma", ainda é inexpressivo o número de educandários que, efetivamente, dispõem de um tal serviço...

Há poucas semanas, comparecemos ao Aeroporto Internacional do Galeão para liberar nossa bagagem pessoal, vinda "desacompanhada" de um país estrangeiro. Nada havia de irregular, tanto que a liberação se procedeu normalmente. Apenas, no processo burocrático de "ir-e-vir", o documento básico da Alfândega recebeu 19 carimbos e 12 assinaturas... E isso numa "época em que o Govêrno está sinceramente empenhado na "Reforma Administrativa".

Esses dois exemplos, que nos ocorrem de imediato, podem ser reconhecidos pelo leitor brasileiro como partes de sua experiência pessoal, e fàcilmente poderiam ser multiplicados para muitas outras áreas. Para nós, isso significa a dúvida e o desafio, sempre presentes, quando se ouve falar em "reformas".

Ninguém põe em dúvida a efetiva necessidade das reformas, nem também a sincera intenção e o dedicado esfôrço daqueles que têm a responsabilidade de efetivar essas reformas. r que usualmente é pôsto em dúvida é o efeito prático de tais reformas, isto é, até que ponto essas reformas conseguem mudar aquilo que se propõem mudar.

Todo processo de reforma corresponde a um esfôrço de mudança planejada, onde o que se pretende é abandonar um

"N. da R.: O autor é especializado em "Desenvolvimento Organizacional pela Universidade da Califórnia, Los Angeles (UCLA). Além de extensiva experiência no Brasil, o Dr. Moura tem atuado como conferencista e especiagrup em sua área na Universidade de Loyola (Nova Orleans), e pertence ao Sciences. 
padrão de realização que tenta resolver os problemas "como sempre foi feito", para agir segundo um nôvo padrão, mais eficiente e consentâneo com as novas situações, recursos e problemas específicos.

É claro que os padrões de comportamento evoluem, não apenas por efeito de reformas, mas até como simples decorrência do tempo. Ou também evoluem quando as situações se tornam tão críticas e desesperadoras que, virtualmente, somos forçados a encontrar novas soluções. Mas êsses processos de mudança são exatamente o que se deseja evitar. No primeiro caso, temos a administração "desligada", ou seja, alheia à evolução das circunstâncias, dos recursos disponíveis, e da natureza dos problemas. É uma espécie de nôvo estilo de "laissezfaire". No segundo caso, temos a administração "por crises", que só é capaz de movimentar-se ante o fato consumado, e sempre atrás de soluções remediativas. Ambos os modelos são indesejáveis e ineficientes, por motivos óbvios.

O que se pretende é mudar, sem dúvida, mas de forma ordenada e planejada. E a mudança planejada é, talvez, o maior desafio à capacidade do Administrador de nosso século.

É a partir das percepções das alterações ocorridas no meio e na cultura, na tecnologia e nos recursos disponíveis, na natureza dos problemas do hoje e do amanhã, que poderemos adaptar-nos a uma "sociedade em mudança", como define Kilpatrick. Temos que realizar um permanente esfôrço de adaptação, avaliando "o que somos e como atuamos" e indagando "como devemos ser e precisamos atuar". Esta comparação entre o estado atual e o estado desejável nos ensinará o que mudar e para que mudar, antes que as crises nos arrastem.

Logo, se uma tal estratégia fôsse regularmente seguida, nem mesmo haveria a necessidade de "reformas", no sentido de mudanças radicais e mais ou menos súbitas. Em seu lugar, haveria um processo contínuo, progressivo e gradativo de renovação, de tal forma que as instituições se manteriam atualizadas.

O que mais freqüentemente ocorre, todavia, é o processo inverso. As instituições - e seus subsistemas - se deterioram de tal maneira, tornam-se tão superados, a ineficiência atinge a tais níveis, que o espantoso não é o vulto necessário às reformas, mas o fato de que, apesar de tudo isso, essas instituições ainda consigam realizar coisas positivas.

A imprevidência das mudanças não planejadas não atinge apenas as instituições de serviço público, tradicionalmente tomadas como "bode expiatório". Também às emprêsas privadas se aplica, em grande parte, o que acabamos de afirmar. 
Se olharmos "do alto e de longe", isto é, sem paixão e sem necessidades de defesa, temos que reconhecer que a capacidade gerencial média, no Brasil, está longe de corresponder às exigências dos tempos atuais.

Embora haja muitas exceções, e com o risco das generalizações excessivas, nosso sentimento é de que não erraríamos muito se destacássemos certas características negativas e positivas do quadro gerencial brasileiro.

Para apenas sumariar, entre as fôrças negativas, tendentes a restringir o desenvolvimento empresarial, poderiamos citar:

a) Pouca profissionalização da atividade gerencial. As pessoas, como regra, chegam à gerência de forma improvisada. Há maior número de gerentes oriundos de formações técnicas, como Engenharia, por exemplo, do que de formação especifica em Administração. As Escolas de Administração são ainda bastante recentes e, relativamente, deficientes. Raros são os cursos destinados a executivos.

b) Como conseqüência, há grande carência de administradores bem qualificados, tanto ao nível do executivo, como ao nível de gerência intermediária. As deficiências são quantitativas e qualificativas.

c) Nem sempre as relações custos-lucros são tratadas adequadamente. Há muita dispersão de esforços, disputas internas e objetivos mal definidos.

d) As emprêsas tendem a ser pouco flexíveis, conservadoras e resistentes à mudança. Estão muito mais prêsas às estruturas que à natureza dos problemas. Há pouca criatividade e a produtividade não é elevada.

e) Os dirigentes exercem sua ação mais baseados no prestígio e poder pessoal que na habilidade de motivar e persuadir seus subordinados. A liderança tende a assumir aspectos paternalistas, e a participação do grupo é bastante reduzida.

f) O padrão usual de comunicação é no sentido vertical e em uma única via, descendente. Há pouca preocupação em dar e obter "feedback". As fontes de decisão estão, no geral, afastadas das fontes de informação.

Ao lado dêsses aspectos negativos, encontram-se também aspectos positivos, fôrças propulsoras que servem ao desenvolvimento empresarial. Entre outras podemos citar:

a) A elevação gradativa dos níveis de educação, traduzindo-se não só em melhoria qualitativa da fôrça de trabalho, como também nos níveis gerenciais. 
b) A consciência nacional, particularmente no meio empresarial, a respeito da necessidade de incrementar o desenvolvimento, de superar as lacunas existentes, inclusive na área de recursos humanos.

c) A interação mais freqüente e estimulante com outras culturas, através de facilidades de bôlsas de estudo, programas editoriais etc.

d) A aceitação do "planejamento integrado", como um valor para todos os níveis e áreas de atividade.

e) Certas características psicossociais do povo brasileiro, como a facilidade de aprendizagem, o individualismo criativo, a adaptabilidade etc.

f) A progressiva elevação dos níveis econômicos, gerando mercados mais competitivos e crescentemente exigentes.

Nossà experiência pessoal não nos autoriza a transpor as observações acima para as instituições de serviço público. Parece-nos, contudo, que na área da administração pública as fôrças restritivas seriam ainda mais potentes, e a elas deveria ser acrescido o caráter necessàriamente político dessas instituições. Haveria uma natural dificuldade, por exemplo, para considerar como "lucro" a prestação de um serviço de alta valia. E, por outro lado, se não é fácil ao administrador privado definir bem suas metas e vincular o sistema de recompensas ao atingimento dessas metas, para o administrador público (que sofre a ilusão de "falta de dono"), sujeito a tantas pressões e limitações, inclusive de ordem legal, a idéia de "eficiência" torna-se um conceito bastante subjetivo.

Constantemente a eficiência é tomada como a "capacidade de fazer os papéis andarem ràpidamente". Principalmente nos níveis intermediários a forma prevalece sôbre a função. 0 administrador fica muito mais preocupado em resguardar sua responsabilidade pessoal do que em resolver os problemas reais de sua área de atividade. Foi a isso que Riggs chamou de "modêlo institucional-legal", tão típico das organizações altamente burocratizadas. ${ }^{1}$ De resto, e para falar franca e rudemente, que diferença faz, para um pequeno chefe de seção, que seu ministério seja mais ou menos eficiente? E se êle tiver o entusiasmo e competência desejáveis, como tantos têm efetivamente, que diferença de tratamento e recompensa êle receberá, em comparação com outros colegas menos eficientes?

1. Riggs, W. - Administração Pública em Países em Desenvolvimento (FGV, Rio, 1968). 
Os esforços de mudança, vindos tradicionalmente de cima para baixo, dirigem sua ação exclusivamente para atingir as estruturas. Mudam-se as organizações, a legislação, as normas, os regulamentos, os quadros de dotação, os organogramas. Mas, as pessoas, ou seja, os que efetivamente manejam as normas e tudo mais, essas permanecem intocáveis.

Só ùltimamente, como vem sucedendo com o presente esfôrço pela Reforma Administrativa, procura-se atuar tanto sôbre as estruturas, quanto sôbre as pessoas. A falha, segundo nossa percepção, é que essa atuação, ao nível dos recursos humanos, se faz apenas na área cognitivo-racional. Instalam-se "cursos" para os agentes da reforma, mas êsses programas de treinamento, mesmo quando muito bem sucedidos, poderão apenas atingir o plano das idéias, noções, informações, conhecimentos ou habilidades. Os programas não são potentes (nem poderiam ser, dadas as suas características exclusivamente racionais) para reformar a única coisa realmente imprescindivel à pretendida Reforma: as atitudes e comportamentos.

Assim como o processo de desenvolvimento econômico Supõe mas não se limita à elevação da renda per capita, assim também a Reforma Administrativa implica, mas não se limita à simplificação burocrática, ao incentivo às delegações de autoridade, e à rapidez de tramitação dos documentos oficiais. A Reforma Administrativa supõe tôdas essas coisas, e muito mais, mas dependerá essencialmente do comportamento individual de cada servidor público, não importa de que nível, e inclusive da atitude positiva com que um modesto funcionário, por exemplo, receber o "cliente e acionista" (ou seja, o homem do povo) que the vem pedir uma simples informação rotineira. Quando o administrador se sentir co-responsável pela eficiência de sua organização, então, seus comportamentos passarão a refletir sua consciência.

As normas, por si só, não mudam atitudes nem comportamentos; mas também a recíproca é verdadeira: atitudes positivas, sòzinhas, não criam normas eficientes. Uma ordem não pode dispensar a outra, nem subestimar seu valor. Não se trata, portanto, de realizar as malsinadas campanhas de "boas" relafões humanas, no estilo do "comece seu dia com um sorriso", ou "o cliente tem sempre razão". Quando muito, isso conseguiria apenas tornar menos antipática a ineficiência.

Sério que se propõe é algo muito mais profundo: um esfôrço das e consciente, capaz de atingir as estruturas, mas através trata, issoas que animam e operam essas estruturas. Nem se trata, igualmente, de discutir a quem deve caber a prioridade. 
Para nós, a prioridade é uma só: o esfôrço deve ser dirigido ao desenvolvimento da eficiência organizacional global e, para isso, será necessário atuar simultâneamente sôbre o sistema e sôbre as pessoas. Ou em outras palavras, tal como as pessoas devem ser treinadas em suas capacidades individuais, também o próprio sistema de trabalho pode e deve ser treinado, como um todo. Êsse é precisamente o campo do "desenvolvimento organizacional", a aplicação prática às estruturas organizacionais dos principais princípios e achados das ciências comportamentais.

O que tem ocorrido, tradicionalmente, e não só no Brasil como no mundo, é o isolamento da ação, ora atuando apenas sôbre as estruturas, ora atuando apenas sôbre as pessoas. A atuação simultânea e integrada só recentemente se desenvolveu como uma metodologia própria. No Brasil, principalmente, o sentido global dessa integração é pràticamente desconhecido e poucas organizações já experimentaram seu valor prático.

O resultado é que, não poucas vêzes, as decisões espelham soluções lógicas e tècnicamente adequadas, mas fracassam quando postas em prática. Ou, se não chegam a fracassar, acabam distorcidas ou bloqueadas, perdendo-se num desgaste sutil, mas muito real.

Há considerável distância entre a tomada de uma decisão, com a conseqüente expedição dos atos administrativos necessários à sua execução, e a adesão interna característica da aceitação real e do comprometimento pessoal por parte dos que vão efetivamente executar essa decisão. Não é, portanto, uma simples questão de "compreender" as razões da decisão e sua lógica específica, mas uma questão de sentir-se pessoalmente envolvido no êxito do processo de execução. Ou seja, as metas organizacionais nunca serão suficientemente fortes para dirigir a ação concreta, a menos que se transformem em objetivos e necessidades pessoais dos elementos humanos que compõem a organização.

Logo, o trabalho que visa à eficiência global de uma organização deverá atender tanto aos aspectos pessoais, como aos aspectos institucionais. Por exemplo, sem o desenvolvimento de seu pessoal uma organização não pode desenvolver-se adequadamente. Mas, e por outro lado, as fôrças que operam ao nivel individual não são potentes para atuarem ao nível dos sistemas de trabalho, e uma organização não se desenvolve como simples e direta resultante do desenvolvimento pessoal de seus elementos humanos. 
Ambos, o indivíduo e a organização, estão de tal forma interligados, e se complementam de tal maneira, que o desenvolvimento de um facilita e prepara o desenvolvimento do outro, mas nenhum dêsses elementos é, por si só, independente.

O grande desafio é realizar a integração dêsses dois niveis de desenvolvimento - pessoal e organizacional - de tal modo que os frutos obtidos em cada área reforcem e ampliem os ganhos obtidos na outra área.

Para pensar numa Reforma, realmente disposta a mudar comportamentos, teremos que pensar numa implantação integrada, onde se cuide não só das normas, como das pessoas; onde se treine não só os indivíduos, como o próprio sistema de trabalho.

Mas não se devem pedir soluções mágicas ou receitas universais. Não há panacéias. Não só as pessoas são diferentes entre si, como também as organizações e, dentro delas, suas unidades de trabalho. Por isso, para cada realidade, e a partir de um razoável trabalho de diagnose da eficiência organizacional, haverá um programa específico e especialmente adaptado.

Talvez um dos aspectos mais imediatamente importantes seja flexibilidade, tanto pessoal, quanto organizacional. Essa flexibilidade - o oposto da imagem estereotipada da burocracia - supõe o desenvolvimento da sensibilidade, como a aptidão para captar as necessidades e perceber as possibilidades, e se estende à capacidade de variar e adaptar o comportamento, em função das necessidades percebidas.

Os programas usuais de treinamento, no sentido tradicional, já fazem muito em favor do desenvolvimento pessoal. Mas, certamente, a parte mais significativa e que levará à flexibilidade, ainda está por se iniciar, pràticamente.

O que êsses programas conseguem, quando conseguem, é o desenvolvimento da competência técnica, isto é, ensinam a fazer as coisas especificas de cada ocupação. Mas êsses programas não cuidam do desenvolvimento da competência interpessoal, que complementa e enriquece a competência técnica. E isso é indispensável, porque, afinal, "administrar é fazer coisas através de pessoas". Logo, essa área interpessoal é tão fundamental quanto a área técnica e, ao nível das chefias, freqüentemente ultrapassa seu valor. Hoje, e graças principalmente aos trabalhos de Chris Argyris e outros, ${ }^{2}$ considera-se que a com-

2. Chris Argyris, Interpersonal Competence and Organizational Effecti-

veness, Homewwood, Illinois, 1962. 
petência global é uma resultante da competência técnica e da competência interpessoal. Ou seja, o chefe de um departamento qualquer não precisa ser, necessàriamente, o melhor especialista dêsse departamento, mas deve ser uma pessoa que, a par de seus conhecimentos técnicos, seja também capaz de conduzir uma equipe integrada e coesa.

Se essa falha existe no campo do desenvolvimento pessoal, no campo do desenvolvimento organizacional, a respeito do treinamento do "sistema", pràticamente nada se faz. As organizações são tratadas de forma "mecânica", e não como "sistemas orgânicos", que exigem uma abordagem "sócio-técnica". Por isso mesmo, não é de admirar que tantas "reformas" se percam no desgaste do tempo e na frieza dos papéis.

A estratégia que defendemos, e que se tem provado eficiente na prática, é a do esfôrço conjugado nos dois niveis já referidos. Naturalmente, para cada caso se partirá de bases apropriadas, com a utilização de técnicas especiais, e perseguindose objetivos específicos.

Em resumo, e para não fugir aos limites dêste artigo, o quadro apresentado abaixo aponta alguns exemplos dos conceitos relevantes ligados à estratégia sugerida: ${ }^{3}$

\begin{tabular}{|c|c|c|c|c|}
\hline Nivel & Bases de Atuação & Enfase & Técnicas & Objetivos \\
\hline Pessoal & $\begin{array}{l}\text { Aptidões individuais } \\
\text { Formação e expe- } \\
\text { riência profissio- } \\
\text { nal } \\
\text { Necessidades, Sen- } \\
\text { timentos e Va- } \\
\text { lôres } \\
\ldots \ldots \ldots \ldots \ldots \ldots\end{array}$ & $\begin{array}{c}\text { Cognitiva } \\
\text { Atitudes } \\
\ldots \ldots \ldots \ldots\end{array}$ & $\begin{array}{l}\text { Treinamento } \\
\text { formal } \\
\text { Desenvolvi- } \\
\text { mento pes- } \\
\text { soal e in- } \\
\text { terpessoal } \\
\ldots \ldots \ldots . . .\end{array}$ & $\begin{array}{l}\text { Competência } \\
\text { Técnica } \\
\text { Competência } \\
\text { Interpessoal } \\
\ldots \ldots \ldots \ldots\end{array}$ \\
\hline $\begin{array}{l}\text { Organiza- } \\
\text { cional }\end{array}$ & $\begin{array}{l}\text { Estrutura formal vs } \\
\text { estrutura in fo r- } \\
\text { mal } \\
\text { Processo vs Tarefa } \\
\text { Problemas e proje- } \\
\text { tos especificos } \\
\text {...................... }\end{array}$ & $\begin{array}{l}\text { Rigidez vs } \\
\text { Flexibili- } \\
\text { dade } \\
\text { Comunica- } \\
\text { ções } \\
\text { Processo } \\
\text { decisório } \\
\text { Solução de } \\
\text { Problemas } \\
\text {............... }\end{array}$ & $\begin{array}{l}\text { Diagnose } \\
\text { organiza- } \\
\text { cional } \\
\text { "Team } \\
\text { building" } \\
\text { Solução de } \\
\text { Problemas } \\
\ldots \ldots \ldots \ldots . . . .\end{array}$ & $\begin{array}{l}\text { Solução de } \\
\text { conflitos } \\
\text { Cooperação } \\
\text { e Competi- } \\
\text { ção Inter- } \\
\text { grupal } \\
\text { Eficiêncla } \\
\text { organiza- } \\
\text { clonal } \\
\text {................ }\end{array}$ \\
\hline
\end{tabular}

3. Moura, Paulo C. Costa, Pessoas, Grupos e Organizações: As Necessidades do Desenvolvimento Integrado (Palestra no XXXVI Leadership Seminar, Interamerican Center of Loyola University, 1970). 
O quadro acima é dado apenas como exemplo dos conceitos relevantes a um programa de desenvolvimento organizacional, sendo que as linhas pontilhadas indicam outros aspectos não abordados neste quadro.

Bases de Atuação: Essas bases são o conjunto de características relevantes, em cada nível de referência, para que, sôbre elas, seja desenvolvido o programa. Por exemplo, qualquer programa formal de desenvolvimento de pessoal deve partir do lastro pessoal dos participantes, e de suas aptidões, pois isso é - que informa a respeito das potencialidades, motivações e limites possíveis da aprendizagem.

Já ao nível organizacional, além das características pessoais, há que considerar outros aspectos, tais como a forma e o funcionamento da estrutura formal, comparada à estrutura informal. Da mesma forma, não só será preciso examinar a tarefa específica do grupo, como o seu processo de trabalho (dinâmica interna, etc).

Enfase: A ênfase corresponde à área para onde deve ser dirigido o esfôrço de desenvolvimento. Ao nível individual, a ênfase será cognitiva e também nas atitudes. Já ao nível organizacional, a ênfase recairá primàriamente em alguns aspectos de fundamental importância: rigidez versus flexibilidade, ou comunicações, ou processos decisórios, como exemplos.

Técnicas: A variedade de técnicas a utilizar é muito ampla. A base dessas técnicas, contudo, está no seu grau de participação e no tipo de motivação que são capazes de obter. As aprendizagens são baseadas na experiência direta, e as possibilidades de transferência são maximizadas. Daí o valor do chamado "método de laboratório", que é por excelência a forma de trabalho nos programas de desenvolvimento organizacional.

Objetivos: Êsses objetivos são os resultados parciais almejados, que culminam com a eficiência organizacional, que é 0 objetivo final.

Há outra maneira, porém, de apreciar a estratégia proposta. Aqui, o objetivo final, que é a eficiência organizacional, é representado como sendo o vértice de uma pirâmide, cujas arestas da base constituem os aspectos pessoais e grupais que o programa procurará desenvolver. Êsses aspectos são:

a) competência técnica;

b) competência interpessoal; 
c) estilo gerencial (estilo de chefia);

d) eficiência de grupo (habilidade de trabalhar em equipe).

Quando êsses aspectos estão razoàvelmente desenvolvidos, novas condições aparecem, como que uma espécie de "lucro marginal", mas lucro êste que é de transcendental significação para a conquista do objetivo final:

a) liderança (funcional);

b) comunicação eficiente (interpessoal e intergrupal);

c) flexibilidade pessoal e organizacional (adaptabilidade);

d) capacidade de solução de problemas (pessoais, interpessoais e intergrupais).

Finalmente, o eixo da pirâmide representa a metodologia geral dos processos de desenvolvimento organizacional. ${ }^{4}$

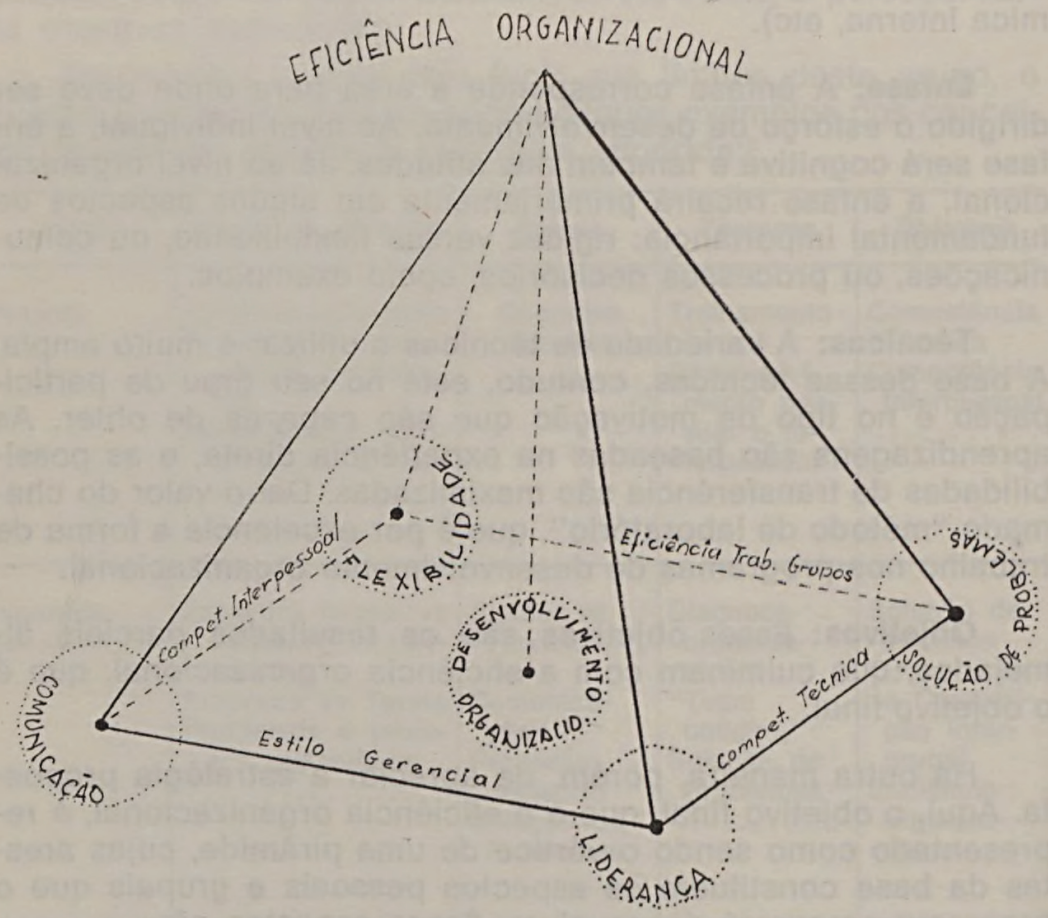

4. Moura, Paulo Costa, Organizational Development and its Possibilities for Organizations of Developing Countries, artigo original a ser publicado no Journal of Applied Behavioral Sciences (NTL Institute). 
Este modêlo piramidal tem sido o roteiro dos nossos trabalhos práticos de consultoria organizacional. Até onde nossa experiência pessoal é válida, o modêlo tem-se mostrado não apenas exeqüível, como também estimulante e prático.

Sua aplicação, contudo, aos problemas objetivos e imediatos do programa de Reforma Administrativa está além de nossa experiência direta. Contudo, e a julgar por situações semelhantes vividas por algumas emprêsas e outras organizações, nas quais temos tido a oportunidade de experimentá-lo, tudo indica que também na administração pública êle se mostrará eficaz.

De qualquer modo, um tal programa teria que obedecer a certas condições básicas, ligadas diretamente à metodologia, e que seriam:

a) existência de um firme e inequivoco apoio por parte da Alta Administração, cujos titulares, tanto quanto possível, deveriam envolver-se pessoalmente nos programas. Preferentemente, o programa deve ser iniciado nos niveis mais elevados;

b) tanto quanto possível, os programas partiriam de situações reais, de problemas significativos e práticos, para os quais os processos tradicionais se têm mostrado impotentes. Logo, a "matéria" não é programada a priori, mas surge das próprias dificuldades do trabalho;

c) tanto quanto possivel, o programa evitará as situações tradicionais de "classes", "alunos" e "instrutores". Ao invés disso, as pessoas participarão em grupos, correspondentes às suas reais unidades de trabalho;

d) deverá ficar bem claro que o objetivo do programa não é "ensinar" coisas a ninguém, mas incrementar a "eficiência organizacional". Isso significa, na prática, conhecimentos e habilidades diretamente relacionados ao comportamento no trabalho, não apenas em têrmos técnicos, mas também em têrmos interpessoais e intergrupais;

e) o processo de aprendizagem será participativo e transacional. Ou seja, as aprendizagens não serão obtidas em "via única". O esfôrço será no sentido de incentivar a troca de informações, através dos mecanismos de "feedback", individual e grupal;

f) o programa deverá ter destacada ênfase no desenvolvimento dos recursos internos da organização conside- 
rada. Com isso, não só se evita a dependência externa de consultores e elementos estranhos, como se estimula a organização a resolver seus próprios problemas, através de uma metodologia adequada;

g) desde que divergências e conflitos são inevitáveis nas situações de trabalho, o programa legitimará o reconhecimento dessas dificuldades, tratando de submetêlas aos métodos de solução de problemas;

h) durante todo o tempo, cada parte do programa procurará incluir, ao final, algum planejamento de ação. Deverá haver oportunidade para revisão periódica dêsses planos, bem como para avaliação dos efeitos obtidos ("feedback").

\section{EM LUGAR DE “CONCLUSÕES”:}

"O dia que passa não volta mais. Nenhum de nós volta a ser jovem de nôvo, para refazer sua vida e instruir-se melhor. Não há remédio para isso. Só nos resta uma coisa: que nos empenhemos em prol dos nossos sucessores. Isto é: conhecendo o caminho pelo qual nossos preceptores nos induziram em êrro, assinalemos o meio de evitar êsses erros." - J. A. Comenius (Didactica Magna, XI, 14 - 1967).

O trecho acima, com mais de três séculos, provém do pedagogo e filósofo checo, que hoje é celebrado como sendo o "Galileu da Educação". O que fêzz Comenius foi deslocar o centro do processo educacional, fazendo-o girar em tôrno do educando, já que êste é o objeto da educação.

Os educadores do mundo custaram a reconhecer o valor e o alcance do pensamento do Mestre. Hoje, suas obras, e especialmente sua Didactica Magna, são tidas como a fonte da renovação pedagógica e a UNESCO patrocina as edições sucessivas do livro.

Os programas de desenvolvimento organizacional não chegam a pretender ocupar um papel semelhante, no terreno da Administração. Mas a revolução, que consiste em centralizar o esfôrço em tôrno do seu objeto formal, é algo que veio para ficar. Desde as novas concepções filosóficas, como em Douglas MacGregor (The Human Side of Enterprise) e sua consagradora separação entre a "Teoria X" e a "Teoria Y", ou como em Rensis Likert (The Human Organization: its Management and Values) com seus não menos famosos "Quatro Sis- 
temas"; ou nas abordagens com enfoque na ação executiva, como em Robert Tannenbaum (Leadership and Organization), ou em Robert Blake (The Managerial Grid); ou ainda nas sistematizações metodológicas, como em Warren Bennis (Changing Organizations), ou em Kenneth Benne (The Planning of Change); e até nos princípios metodológicos, como em Leland Bradford (T-Group Theory and The Laboratory Method), ou Edgard Schein (Personal and Organizational Change Through Group Methods), o conhecimento disponível e as realizações já obtidas são uma garantia suficiente de que é possível ao Administrador de hoje encontrar melhores soluções aos problemas e desafios de uma sociedade em constante e rápida transformação.

Como frisou Comenius, "o dia que passa não volta mais", e "só nos resta uma coisa: que nos empenhemos em prol dos nossos sucessores". Até que ponto os administradores desejam evitar os mesmos erros do passado?

É o desafio. 